\title{
Collective control strategy for a cluster of stall-regulated offshore wind turbines ${ }^{\text {th }}$
}

\author{
S. Hur ${ }^{\mathrm{a}, *}$, W. E. Leithead ${ }^{\mathrm{a}}$ \\ ${ }^{a}$ Department of Electronic and Electrical Engineering, University of Strathclyde, Glasgow \\ G1 $1 X W$, United Kingdom
}

\begin{abstract}
The power converter is one of the most vulnerable components of a wind turbine. When the converter of an offshore wind turbine malfunctions, it could be difficult to resolve due to poor accessibility. A turbine generally has a dedicated controller that regulates its operation. In this paper, a collective control approach that allows a cluster of turbines to share a single converter, hence a single controller, that could be placed in a more accessible location. The resulting simplified turbines are constant-speed stall-regulated with standard asynchronous generators. Each cluster is connected by a miniAC network, whose frequency can be varied through a centralised AC-DCAC power converter. Potential benefits include improved reliability of each turbine due to simplification of the turbines and enhanced profit owing to improved accessibility. A cluster of 5 turbines is assessed compared to the situation with each turbine having its own converter. A collective control strategy that acts in response to the poorest control is proposed, as opposed to acting in response to the average control. The strategy is applied to a cluster model, and simulation results demonstrate that the control strategy could be more cost-effective than each turbine having its own converter, especially with optimal rotor design.
\end{abstract}

Keywords: offshore wind farm control, collective control, wind turbine control, wind turbine modelling, stall-regulated wind turbines.

\footnotetext{
This work was supported by the UK EPSRC (the Supergen Wind Energy Technologies Consortium) Platform Grant EP/H018662/1.

${ }^{*}$ Corresponding author

Email addresses: hur.s.h@ieee.org (S. Hur), w.leithead@strath.ac.uk
} (W. E. Leithead) 


\section{Introduction}

There is much interest in renewable energy due to concern over the environment, and wind is considered to be one of the most promising renewable energy sources. One of the reasons is that wind is an infinite and free source of energy with no harmful waste products. A wind turbine converts the kinetic energy from the wind into mechanical energy. It is then converted into electricity, which is sent to a power grid. There are two basic configurations, vertical and horizontal-axis wind turbines. This paper is concerned with horizontal-axis wind turbines, having three blades [1]. The yaw mechanism, which is responsible for orientating the turbine towards the wind, is ignored in this paper.

The power converter is one of the most vulnerable components of a wind turbine. When the converter of an offshore wind turbine develops a fault, it could be difficult to repair due to accessibility problems, e.g. as a result of bad weather, etc. Normally, a wind turbine is equipped with a dedicated full envelope controller that regulates its operation. In this paper, a collective control approach that allows a cluster of (5 to 10) wind turbines to share a single converter (hence a single controller), which could be located in a place where it is more accessible away from the turbines, is proposed. Maintaining a dedicated power converter for an individual turbine and placing each of them away from the turbines (i.e. for improved accessibility) would be significantly more expensive, and, therefore, a single converter is shared between all the turbines in a cluster. The resulting simplified turbines are constant-speed stall-regulated [2] machines with standard asynchronous generators. Constant-speed and stall-regulated turbines are known to be more reliable than variable-speed and pitch-regulated turbines, respectively. Each cluster is connected by a mini-AC grid (or network), whose frequency can be varied through a centralised AC-DC-AC power converter.

A number of clusters with its own dedicated mini-grid would be linked to constitute an offshore wind farm, which could subsequently be interconnected with an onshore wind farm through an appropriate transmission system. Various types of transmission system can be found in the literature, including the ones that exploit the high-voltage direct current (HVDC) $[3,4,5]$, but this topic is not discussed in this paper.

The AC frequency of the cluster is altered by a controller responding to measurements of generator torque (or generator power) from each turbine within the cluster, thus, varying the rotor speed of the turbine. If each 
turbine experienced the same wind speed, the regulation of each turbine would be almost identical to the situation with each turbine having its own converter and controller. However, each turbine experiences a different wind speed, and, therefore, the operational state of each turbine deviates from the required control strategy to the extent that drive-train torque and rotor speed transients are increased. When the cluster size becomes too large, the regulation would become unacceptable.

The idea of sharing a single converter between several turbines is not common but has been considered in the literature. In $[6,7]$ a single converter is also shared between several turbines but for different purposes; that is, for the purpose of re-powering smaller old wind turbines (e.g. $35 \mathrm{~kW}$ turbines) and for the purpose of reducing fluctuations on the wind farm power output in above rated wind speed (whereas the full operational envelop of wind speed is considered in this paper) focusing on the generator, respectively. In this paper, the impact of the proposed collective control strategy on the turbines' operation, including power efficiency and loads on the turbines, is studied. Another significant difference between these studies and the study presented here is that in $[6,7]$, it is assumed that each turbine is capable of providing an individual control by pitching while all the stall-regulated wind turbines considered in this study share a single collective control, i.e. the sole control action here is the collective control. Moreover, since the turbines considered in $[6,7]$ are relatively small, it is assumed that each turbine experiences the same wind speed therein. In this study, each turbine is significantly larger, being a $5 \mathrm{MW}$ machine, and the turbines are therefore placed approximately $1 \mathrm{~km}$ apart. Hence, each turbine experiences a unique wind speed (although correlated to be realistic), significantly impacting on the control performance.

The main contribution of this paper can now be summarised as proposing, implementing and testing the set-up whereby a single power converter and the controller are shared between multiple turbines. The novel objective is achieved by the use of a collective control strategy that is further improved to take account of the worst performing turbines when necessary. Potential benefits include improved reliability of each turbine due to simplification of the turbines and increased profit as a result of improved accessibility. Reliability improves further due to the use of constant-speed and stall-regulated wind turbines as opposed to variable-speed and pitch-regulated wind turbines. Note that even though the wind turbines are constant-speed machines [8], a variable-speed operating strategy is exploited in this study because the frequency of each cluster can be altered through a centralised AC-DC-AC 
power converter. The disadvantage is that the control of each turbine is deteriorated with implications of potentially reduced energy capture and increased loads. These disadvantages undoubtedly become greater as the size (i.e. the number of turbines) of the cluster increases. In this paper, a cluster consisting of 5 turbines is investigated in comparison to the situation with each turbine having its own converter and controller. In order to develop the proposed collective control scheme, a wind turbine controller based on an existing strategy is first designed and implemented; that is, this controller serves as the basis for the collective control scheme. The importance of the choice of rotor design on the performance of the collective control strategy is also discussed.

A modified version of the wind turbine reported in [9] is modelled in Matlab/SIMULINK ${ }^{\circledR}$ in Section 2. The parameters of the SUPERGEN Wind Energy Technologies Consortium (Supergen) 5MW turbine are exploited. This model is subsequently utilised as a control model [10] for designing a full envelope controller for the turbine as reported in Section 3. Model Predictive Control (MPC) [11] is chosen as the controller design algorithm. The process input and output are grid frequency and generator torque, respectively, in contrast to the standard control strategy in which the process input and output are generator torque demand and generator speed, respectively. A stall-regulated variable-speed operating strategy [12] over the whole operational envelope is designed for a single turbine and its performance assessed in Section 3.

Subsequently, a cluster model of 5 wind turbines is developed by replicating the single turbine model in combination with a DNV-GL-Bladed (Bladed) model of the same turbine (i.e. Supergen 5MW exemplar wind turbine) in Section 4. Suitable stochastic models for the wind speeds for each turbine, taking account of the correct correlation for layout of the cluster, are incorporated into the cluster model. As with the single turbine case, the plant input and output for the cluster are the frequency of the local network connecting the cluster and measurements of generator torque (or power) from each turbine, respectively. A collective control strategy for the cluster of turbines that acts in response to the turbines with the poorest control when necessary is proposed, and the simulation results are compared with the situation with each turbine having its own converter and controller. Conclusions are drawn and future work discussed in Section 5. 


\section{Modelling}

A simple Matlab/SIMULINK simulation model is developed in this section, based on the equations provided in [9]. This simplified model is the control design model exploited for designing the controllers in Sections 3 and 4. Research is still being conducted to develop more detailed models to predict wind turbines' response and performance more accurately [13, 14], but the controllers are still designed based on simplified models similar to the one reported in this section $[15,16,17]$. In fact, it is recommended that the control design model be kept not too complex since it could cause the controllers to be active at high frequencies and to lack robustness. A high fidelity aero-elastic model (of the same turbine) in Bladed is thus utilised to simulate the plant in Section 3. This model produces additional dynamics enabling further results to be obtained, including all significant variables and loads and lifetime equivalent fatigue load estimates.

The model employs the parameters of the 5MW exemplar wind turbine of Supergen. As the size of a cluster increases, each wind turbine would experience greater drive-train load transients and fluctuations in generated power in above rated wind speed as a result of increasing differences in the wind speed each turbine experiences. In order to ameliorate these effects to an extent, the model replaces the existing synchronous generator with an asynchronous induction generator since the latter would provide considerably greater damping.

\subsection{Wind speed model}

The wind stochastically varies with time and continuously interacts with the rotor [18]. The effective wind speed is wind speed averaged over the rotor area so that the power spectrum of aerodynamic torque remains intact. In this paper, it is derived by filtering the point wind speed [12] through the filter introduced in [18]. The point wind speeds that take account of the correlation of the cluster layout is obtained from Bladed. The effective wind speeds are required to simulate the Matlab/SIMULINK models in Section 4. In Section 3, the wind is simulated in Bladed, and, thus, the effective wind speed model is not required. Turbulence intensity of $10 \%$ is employed throughout this paper. 


\subsection{Aerodynamics}

The aerodynamic torque, $T_{f}$, has a nonlinear relationship with the effective wind speed, $U$, and the rotor speed, $\Omega$, as follows:

$$
T_{f}=\frac{1}{2} \rho \pi U^{2} R^{3} \frac{C_{p}(\lambda)}{\lambda}
$$

where the tip-speed ratio, $\lambda$, is defined as

$$
\lambda=\frac{R \Omega}{U}
$$

$R$ denotes the rotor radius, $C_{p}$ the aerodynamic power coefficient, and $\rho$ the air density. From equations (1) and (2), it is clear that, for each wind speed, the maximum power is produced at the value of the tip-speed ratio for which the aerodynamic power coefficient is at a maximum. Hence, the value of $T_{f}$ that corresponds to the maximum power values is proportional to $\Omega^{2}$.

\subsection{Drive-train Dynamics}

Rotor speed, $\Omega$, and generator speed, $w_{g}$, are dependent on aerodynamic torque, $T_{f}$, and generator reaction torque, $T_{e}$ as follow

$$
\left[\begin{array}{c}
\Omega \\
w_{g}
\end{array}\right]=\left[\begin{array}{ll}
A(s) & B(s) \\
C(s) & D(s)
\end{array}\right]\left[\begin{array}{c}
T_{f} \\
T_{e}
\end{array}\right]
$$

The simplified model introduced here neglects the intermediate and high frequency components, and $A(s),-B(s) / N, C(s) / N$, and $-D(s) / N^{2}$ are reduced to

$$
\frac{1}{\left(\left(I_{1}+N^{2} I_{2}\right) s+\left(\gamma_{1}+N^{2} \gamma_{2}\right)\right)}
$$

where $I_{1}\left(=3.9 \times 10^{7} \mathrm{~kg} \mathrm{~m}^{2}\right)$ denotes rotor inertia, $I_{2}\left(=534.1 \mathrm{~kg} \mathrm{~m}^{2}\right)$ generator inertia, $N(97)$ gearbox ratio, $\gamma_{1}\left(=1.5 \times 10^{5} \mathrm{Nm} / \mathrm{rad} / \mathrm{s}\right)$ low-speed shaft external damping coefficient, and $\gamma_{2}(=5 \mathrm{Nm} / \mathrm{rad} / \mathrm{s})$ high speed shaft external damping coefficient. 


\subsection{Induction Generator Unit Dynamics}

The model introduced in [9] includes a synchronous generator, but the model introduced here is modified to include an induction generator as previously mentioned. The the induction generator model is represented by the following equation

$$
0.08 \dot{T}_{e}+T_{e}=5 \times 10^{4}\left(w_{g}-\frac{f_{g}}{n_{p}}\right)
$$

where $f_{g}$ denotes the grid frequency and $n_{p}$ the number of poles.

\section{Full Envelope Control}

The controller design for regulating variable-speed wind turbines could be categorised into two parts - the determination of the operating strategy of the controller and its synthesis. Recall that although the turbines are constantspeed machines, variable operating strategy is exploited in this study since the frequency of each cluster can be varied through a centralised AC-DCAC power converter. The method of synthesis is Model Predictive Control (MPC) although other control algorithms, including Linear Quadratic Gaussian (LQG) [19], [20] and $\mathrm{H}_{\infty}$ [21], [22], would also be equally pertinent.

Normally, the determination of control strategy is more challenging as the implementation issues such as accommodation of the variation in turbine dynamics, and thus control regulation, over the full operational envelope, actuator constraints, which are most significant to the application, switching transients, start-up and shut-down all need to be identified and the controller realisation that best resolves them chosen. That is, this is related to nonlinear aspects of the turbine dynamics, and a careful investigation of the global behaviour of the system is essential. In this study, a control strategy that has been thoroughly tested and is currently in operation in real life is exploited. The details can be found in [23], but the control regulation and switching parts are briefly revised in this section.

\subsection{Rotor Characteristics and Control Strategy}

Two rotors having different aerodynamic characteristics are initially considered. The aerodynamic power coefficients for Rotor A [9] and Rotor B (provided by Supergen) are presented in Figure 1, which demonstrates that Rotor A has a peaked $C_{p}-\lambda$ curve whereas Rotor B has a broad flat $C_{p}-\lambda$ curve. The difference impacts greatly on the control strategy. 


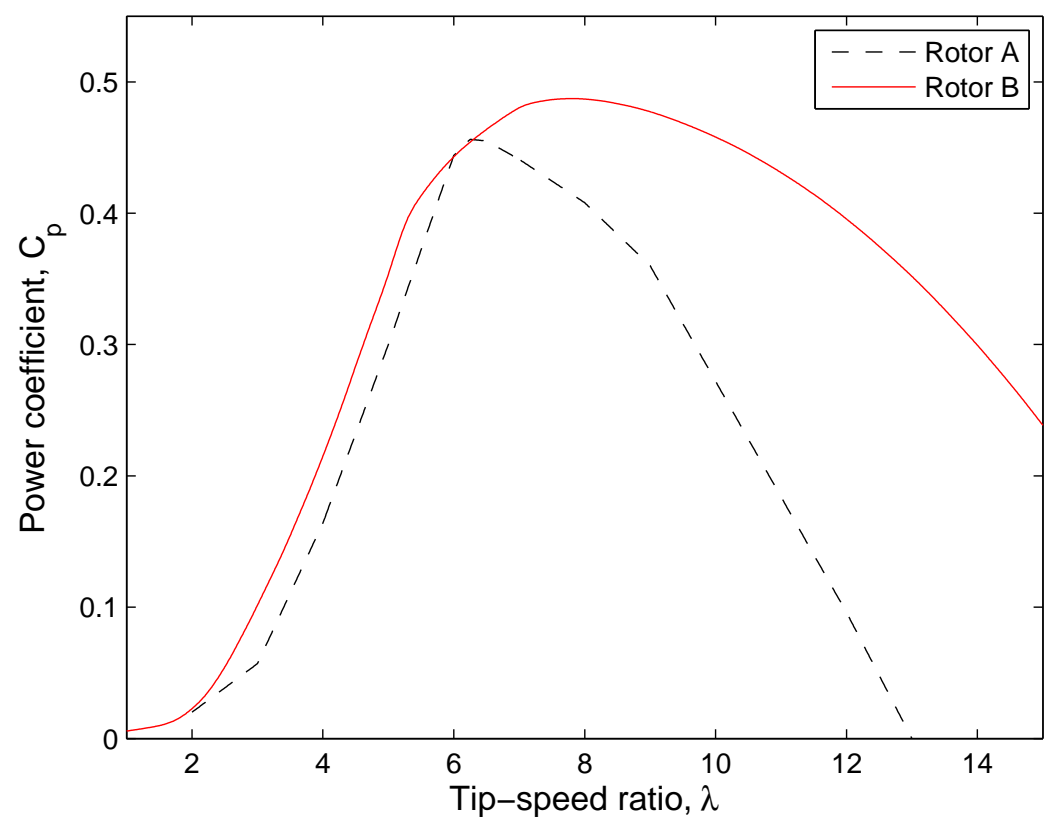

Figure 1: $C_{p}-\lambda$ curves with flat and peaked characteristics.

The control strategies for both rotors are depicted in Figures 2 and 3. For both, in mode 1, a constant rotor speed is maintained in the lowest wind speeds; in mode 2 , the rotor speed is varied to maximise the aerodynamic efficiency in intermediate wind speeds; in mode 3, constant rotor speed (higher than the first mode) is again maintained in higher wind speed; in mode 4, the rotor stalls to maintain rated power in above rated wind speeds. In Figure 2 , mode 3 is only present to reduce the overshoot that could occur when switching between modes 2 and 4 .

Rotor A and Rotor B are, respectively, suitable for stall regulation and pitch regulation because, as depicted in Figures 2 and 3, rotor speed needs to be reduced much more rapidly as it switches from mode 3 to mode 4 with Rotor $\mathrm{B}$ (i.e. the distance between mode 3 and the stall region is significantly larger with Rotor B as depicted in the figures). However, when the number of turbines in each cluster increases to 5 , reduced energy capture cannot be avoided. Rotor A is more vulnerable to reduced energy capture than Rotor B since turbines with Rotor A need to operate much closer to the stall region 


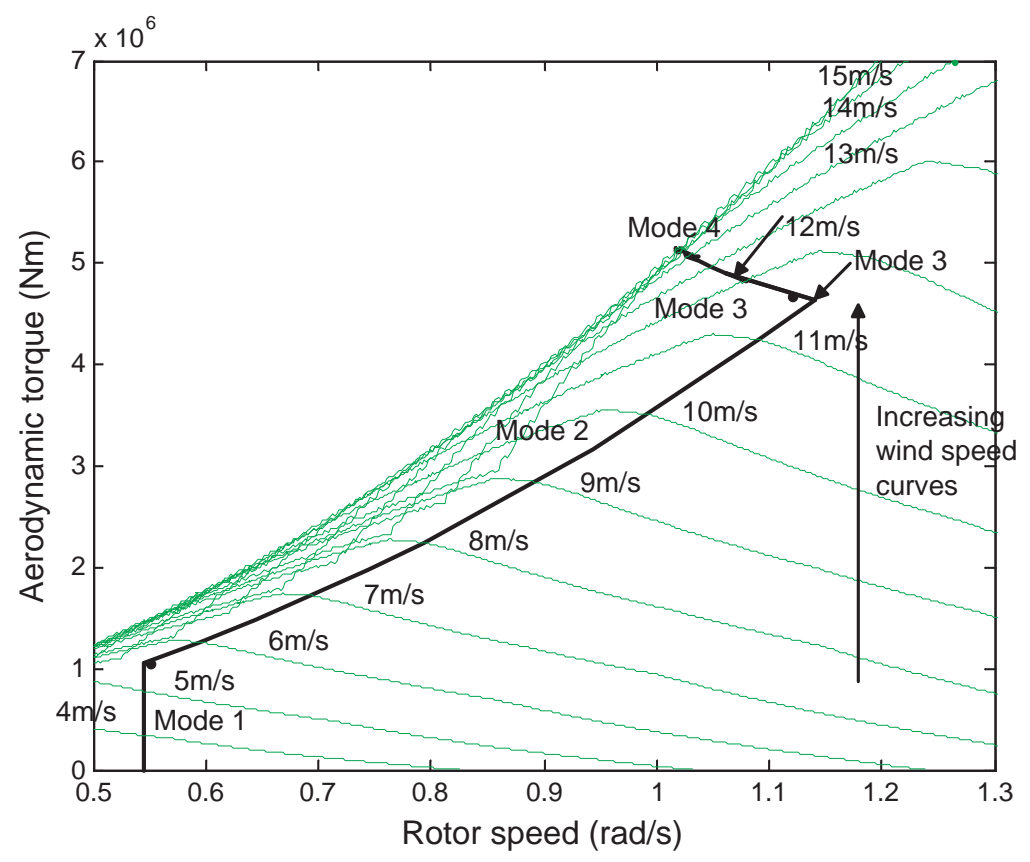

Figure 2: Operational strategy using Rotor A on the torque/speed plane.

as illustrated in the figures.

In summary, Rotor A provides improved results when there is only one turbine in a cluster, and Rotor B outperforms Rotor A for a cluster of 5 turbines. Consequently, it would be appropriate to exploit a rotor that shares the characteristics of Rotor A and Rotor B. Unfortunately, such a rotor is not available for this study, and Rotor B is utilised throughout this paper to maintain improved energy capture.

\subsection{Control Regulation}

In mode $2, T_{f}$ is caused to track the $C_{p \max }$ curve. Because the $C_{p \max }$ curve is proportional to $\Omega^{2}$, the corresponding output, $y_{i}$, which is also the input to the controller as depicted in Figure 4, is defined as follows [23]

$$
y_{i}=T_{f, i}-k \Omega_{i}^{2}
$$

for $i=1, \ldots, N$, where $N$ denotes the number of turbines in each cluster. 


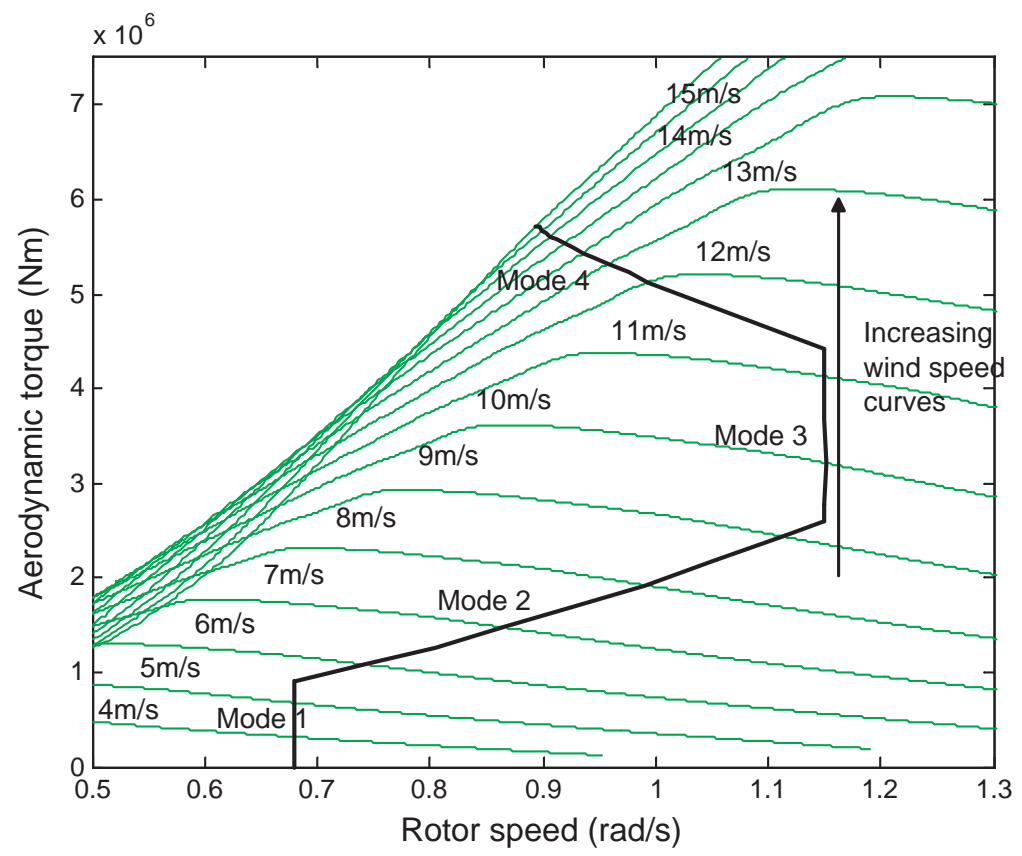

Figure 3: Operational strategy using Rotor B on the torque/speed plane.

$T_{f, i}$ cannot be directly measured and is, therefore, estimated from the measured drive-train torque, $T_{e, i}$. The equation thus becomes

$$
y_{i}=N T_{e, i}+h(s) \Omega_{i}-k \Omega_{i}^{2}
$$

In order to obtain $h(s)$, equation (3) can be re-expressed as

$$
T_{f, i}=\frac{\Omega_{i}}{A(s)}-\frac{B(s)}{A(s)} T_{e, i}
$$

Since $B(s)=-A(s) N$ (refer to equation (4)), $T_{f, i}$ in equation (8) can be redefined as

$$
T_{f, i}=A^{-1}(s) \Omega_{i}+N T_{e, i}
$$

Hence, $h(s)$ is obtained as

$$
h(s)=\frac{1}{A(s)}
$$




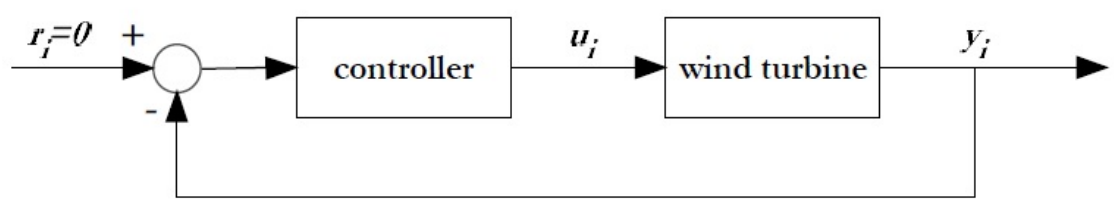

Figure 4: Control scheme.

However, since the derivative term in $h(s)$ could amplify the high frequency noise, a low-pass filter is introduced, modifying $h(s)$ in equation (10) as follows

$$
h(s)=\frac{b}{A(s)(s+b)}
$$

where $b$ is in the range of 5 to $10 \mathrm{rad} / \mathrm{s}$.

In mode $3, T_{f, i}$ is caused to track the constant rotor speed segment of the operating strategy curve shown in Figures 2 and 3. The corresponding output is, therefore, as follows

$$
y_{i}=\Omega_{i}-\Omega_{0}
$$

where $\Omega_{0}$ denotes the relevant constant rotor speed. This particular regulation could lead to significant reduce energy capture, but it is necessary to include this regulation since it enables smoother transition between modes 2 and 4 .

In mode 4 , the rated power, $P_{0}$, is maintained, in above rated wind speed, by causing $T_{f, i}$ to track the constant power curve. The corresponding output is, therefore, as follows

$$
y_{i}=T_{f, i}-\frac{P_{0}}{\Omega_{i}}
$$

As with equation (7), equation (13) is modified to

$$
y_{i}=T_{e, i}+h(s) \Omega_{i}-\frac{P_{0}}{\Omega_{i}}
$$




\subsection{Linearisation}

From the nonlinear model introduced in Section 2, together with either equation (6), (12) or (14), depending on the mode of operation, a state space model can be linearised for the three operating points, modes 2,3 and 4, as follows:

$$
\begin{aligned}
& \Delta \mathbf{x}_{k+1}=A \Delta \mathbf{x}_{k}+B \Delta u_{k} \\
& \Delta y_{k}=C \Delta \mathbf{x}_{k}
\end{aligned}
$$

where $A, B$, and $C$ are the state space matrices. $\Delta y_{k} \in \mathbb{R}^{n}, \Delta u_{k} \in \mathbb{R}^{m}$ and $\Delta \mathbf{x}_{k} \in \mathbb{R}^{r}$ (where $n, m$, and $r$ are respectively 1,3 , and 1) are defined as

$$
\begin{aligned}
\Delta y_{k} & =y_{k}-y_{k, o} \\
\Delta u_{k} & =u_{k}-u_{k, o} \\
\Delta \mathbf{x}_{k} & =\mathbf{x}_{k}-\mathbf{x}_{k, o}
\end{aligned}
$$

\subsection{Model Predictive Control}

For the linear model shown in equations (19) and (20), the prediction equations for MPC can be derived as [24]

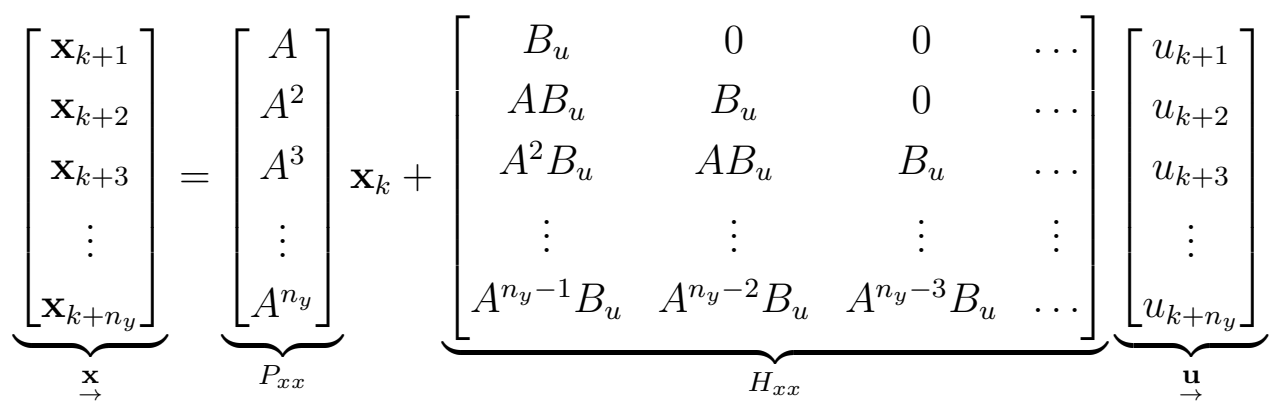

$$
\begin{aligned}
& \mathbf{x}_{k+1}=A \mathbf{x}_{k}+B u_{k} \\
& y_{k}=C \mathbf{x}_{k}
\end{aligned}
$$


and

$$
\underbrace{\left[\begin{array}{c}
y_{k+1} \\
y_{k+2} \\
y_{k+3} \\
\vdots \\
y_{k+n_{y}}
\end{array}\right]}_{\mathbf{y}}=\underbrace{\left[\begin{array}{c}
C_{g} A \\
C_{g} A^{2} \\
C_{g} A^{3} \\
\vdots \\
C_{g} A^{n_{y}}
\end{array}\right]}_{P} \mathbf{x}_{k}+\underbrace{\left[\begin{array}{cccc}
C_{g} B & 0 & 0 & \ldots \\
C_{g} A B & C_{g} B & 0 & \ldots \\
C_{g} A^{2} B & C_{g} A B & C_{g} B & \ldots \\
\vdots & \vdots & \vdots & \vdots \\
C_{g} A^{n_{y}-1} B & C_{g} A^{n_{y}-2} B & C_{g} A^{n_{y}-3} B & \ldots
\end{array}\right]}_{H}
$$

where $n_{y}$ denotes prediction horizon, and $\underset{\rightarrow}{\mathbf{u}}$ is

$$
\left[\begin{array}{llllllll}
u_{k+1} & u_{k+2} & \ldots & u_{k+n_{u-1}} & u_{k+n_{u}} & u_{k+n_{u}} & \ldots & u_{k+n_{u}}
\end{array}\right]^{T}
$$

if control horizon, $n_{u}$, is smaller than prediction horizon, $n_{y}$. Prediction horizon $n_{y}$ should not be smaller than $n_{u}$.

The control solution is obtained by minimising the following objective function [25]

$$
J=\left\|r-H \underset{\rightarrow}{\mathbf{u}}-P \hat{\mathbf{x}}_{k}-L \mathbf{d}\right\|_{2}^{2}+\lambda\|\underset{\mathbf{u}}{\mathbf{u}}\|_{2}^{2}
$$

subject to the following constraints

$$
\begin{aligned}
\underline{u}_{i} & \leq u_{i} \leq \bar{u}_{i} \\
\Delta \underline{u}_{i} & \leq \Delta u_{i} \leq \Delta \bar{u}_{i}
\end{aligned}
$$

where $\bar{u}_{i}$ and $\underline{u}_{i}$ denote the upper and lower limits on $u_{i}$, respectively, and $\Delta \bar{u}_{i}$ and $\Delta \underline{u}_{i}$ the upper and lower limits on $\Delta u_{i}$, the rate of change of input, respectively. $r$ denotes the reference signal, $H$ and $P$ are from equation (22), and $L$ is a vector of ones. The offset $\mathbf{d}(=\mathbf{y}-\hat{\mathbf{y}})$ is included to produce unbiased predictions and offset correction. The first $\|$.$\| term is to reduce$ the reference tracking error and the second $\|$.$\| term to reduce the control$ action. Consequently, $\lambda$ gives a trade-off between two conflicting problems. $\hat{\mathbf{x}}_{k}$ comes from the internal model here but the use of a state estimator such as the Kalman filter could also be appropriate. 


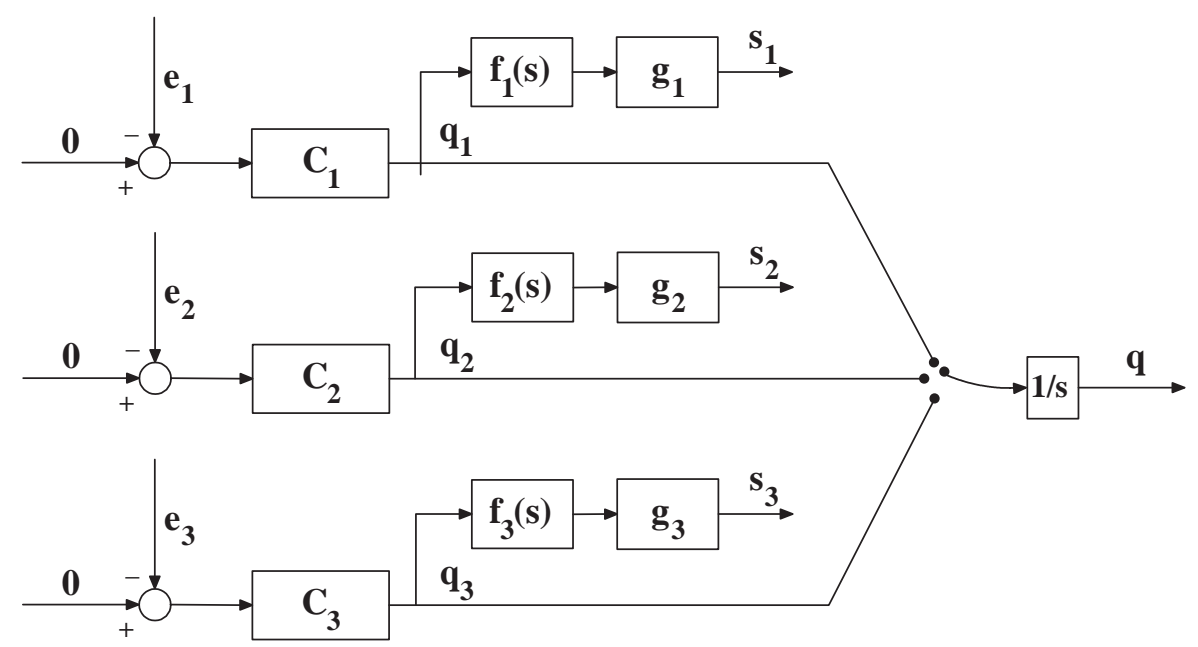

Figure 5: Switching procedure.

\subsection{Switching}

The controller needs to operate over the full operational envelope of wind speed as described in Section 3.1. The MPC designed linear controllers are combined through a switching procedure in a smooth manner that avoids the introduction of large transients. One of the switching procedures introduced in [23] is employed.

As illustrated in Figure 5, switching between the three Single Input Single Output (SISO) controllers (i.e. $C_{1}, C_{2}$ and $C_{3}$, respectively for modes 2,3 and 4) is required. The integral action, present in all the controllers, is placed after the switch, thereby smoothing the discontinuities, which occur on switching, and avoiding integral wind-up, which would otherwise occur because the mean value of $e_{i}$ (for $i=1,2,3$ ) is not zero when $q$ acts in response to $q_{i}$ (for $i=1,2,3$ ). The difference in the spectra is partially removed by the controllers $C_{1}, C_{2}$ and $C_{3}$, but a residual difference, mainly due to the relationships of $e_{i}$ (for $i=1,2,3$ ) to the wind speed, remains. The filters, $f_{i}(s)$ (for $i=1,2,3$ ), are designed to reduce this residual difference and also the high frequency components of the spectra to reduce chattering due to too rapid switching. Also, hysteresis needs to be incorporated to remove chattering even further. Finally, the scaling constants, $g_{i}$ (for $i=1,2,3$ ), are present to adjust the relative distances to the curve. 


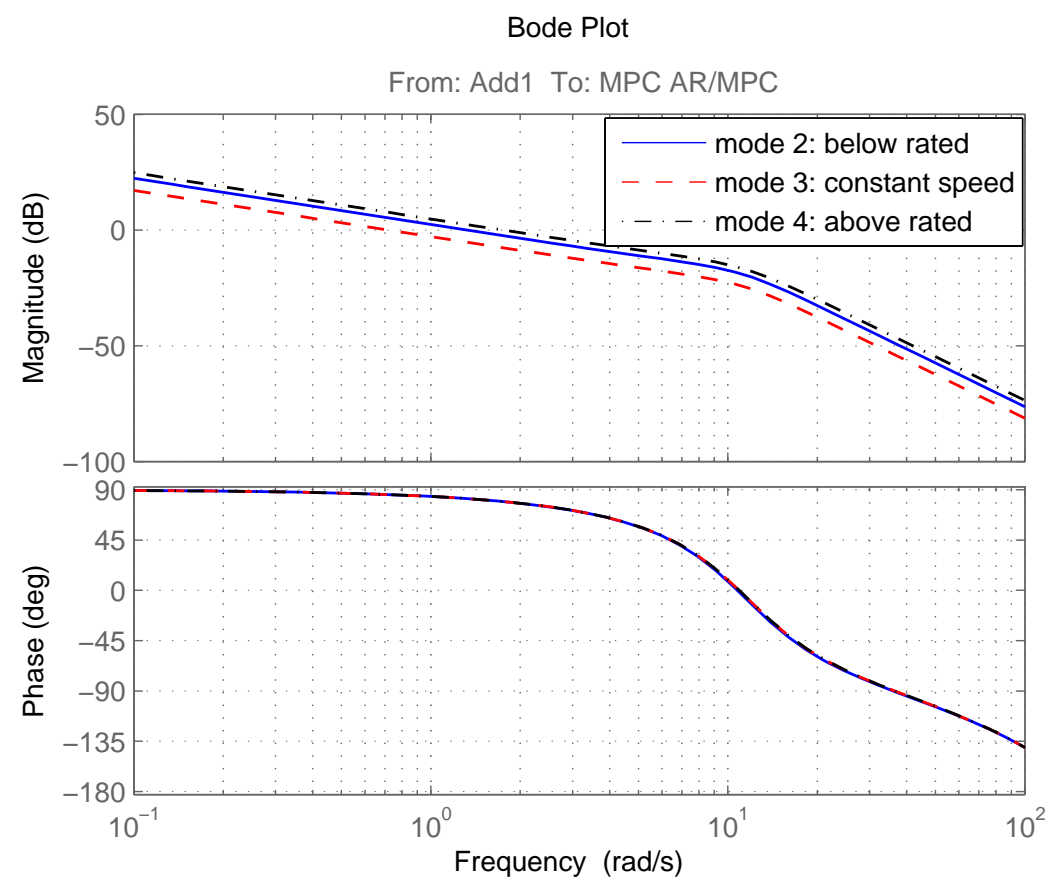

Figure 6: Open-loop frequency responses (the controller applied to the turbine model) in modes 2,3 and 4 .

\subsection{Simulation Results}

The controller is initially tuned through the application of the controllers to the Matlab/SIMULINK model. The open-loop frequency response (the controller applied to the model with open-loop) at each operating point is depicted in Figure 6. Each gain crossover frequency is near $1 \mathrm{rad} / \mathrm{s}$, which implies that the control action would be neither too relaxed nor too aggressive [26]. It is also indispensable to ensure that the controllers at each mode are stable [27, 28]. As depicted in the figure, phase margins for the below rated (mode 2), constant speed (mode 3 ) and above rated (mode 4) controllers are approximately 81,84 and $75^{\circ}$, respectively, indicating that their closed-loop responses would be stable. Note that the MPC controllers incorporate a positive feedback, i.e., the phase at the gain crossover frequency should be added to a multiple of 360 degrees instead of 180 degrees to derive the phase margin.

Once the controller is designed and tuned against the Matlab/SIMULINK 


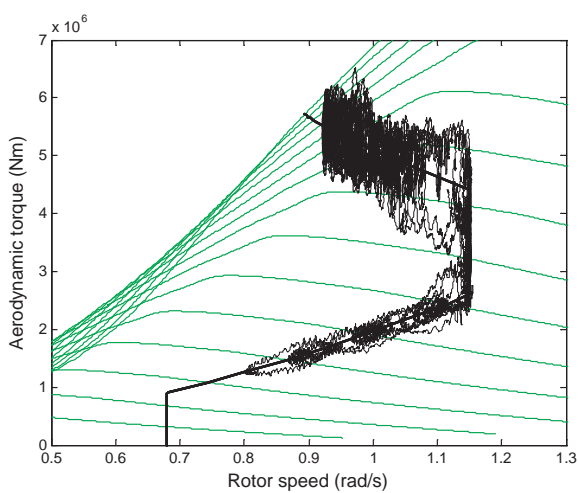

(a) application to Bladed model.

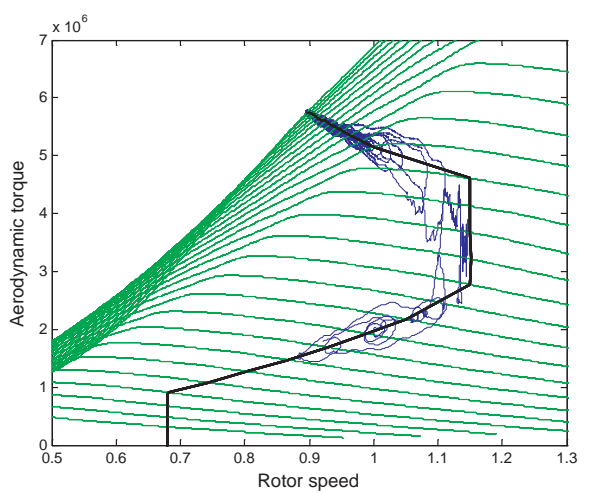

(b) application to simplified model.

Figure 7: Behaviour of the turbine on the torque/speed plane.

model (i.e. the control model), the controller is applied to the Bladed model (i.e. the plant model of the same Supergen 5MW exemplar turbine) and detuned. The differences between the control and plant models provide a degree of model-plant mismatch to test the robustness of design. Moreover, aero-elastic models, such as the plant model, includes more dynamics enabling further results to be obtained, including all significant variables and loads and lifetime equivalent fatigue load estimates. Note that the use of aero-elastic models is common in controller design before the application to the real-life wind turbines. StrathControl Gateway, a commercial software package that fully integrates the simulation, is utilised to allow the controller designed in Matlab/SIMULINK to be applied to the Bladed model.

Figures 7 and 8 depict the behaviour of the control strategy on the torque/speed planes [23]. In order to tune the controller, it is first applied to the control design model, i.e. the simplified model developed in Matlab/SIMULINK, as depicted in Figures $7 \mathrm{~b}$ and $8 \mathrm{~b}$, and subsequently to the Bladed model as shown in Figures 7a and 8a. Recall that the Bladed model simulates the plant in this paper. The simulations in this section are carried out at mean wind speeds of $8,9,11,12,14$ and $16 \mathrm{~m} / \mathrm{s}$ for the duration of $500 \mathrm{~s}$

As previously mentioned, the controller employs a switching mechanism that has been tested exhaustively [23]. It is a switching mechanism that is currently exploited in industry and is briefly revised in Section 3.5. Since 
this rotor is not originally designed for stall-regulation, the overshoots that occur when switching, especially between mode 3 and mode 4, are inevitable. Nonetheless, the perturbations of aerodynamic power and generator power stay within acceptable $20 \%$ at wind speed above rated when applied to the Bladed model. Recall that the results can be improved significantly by utilising Rotor A, but Rotor B needs to be used here because Rotor B outperforms Rotor A when there are 5 turbines in a cluster, as discussed in the following section. The difference between the results when the controller is applied to the Matlab/SIMULINK and Bladed models mainly arises from rotational sampling and unsteady aerodynamics, which are included in the Bladed model only. Rotational sampling and unsteady aerodynamics should not impact on the control design [2], and thus it is evident that the use of a simplified model is sufficient for designing a wind turbine controller. Moreover, successful application to the Bladed model demonstrates that the controller designed based on the simplified model is robust. This controller serves as the basis for the collective control strategy introduced in Section 4.

The power efficiency at wind speed below rated cannot be obtained from Bladed simulations since the effective wind speed [18], required for the calculation of the power efficiency, is not available. However, it is illustrated in [29] that the power efficiency obtained by applying the controller to the Matlab/SIMULINK model, instead, provides almost identical results. Therefore, the power efficiency (through the application of the controller to the Matlab/SIMULINK model as opposed to the Bladed model) at wind speed below rated (i.e. $8 \mathrm{~m} / \mathrm{s}$ ) is plotted in Figure 9. It stays relatively high at above $97.5 \%$. Improvement is possible at the cost of "generator" power efficiency. The average power efficiency over time is $99.6 \%$ as shown in Figure 9. 


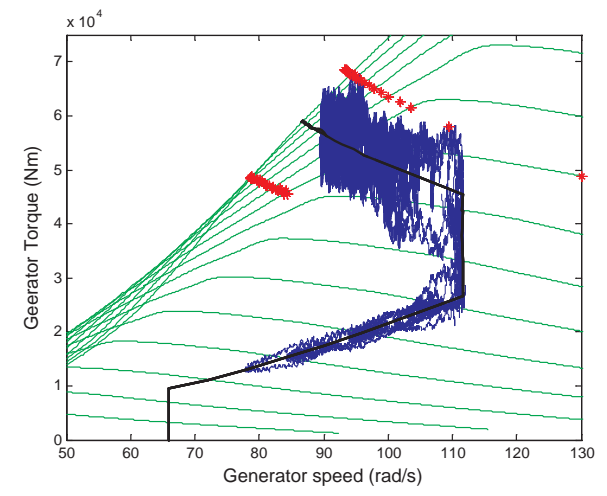

(a) application to Bladed model.

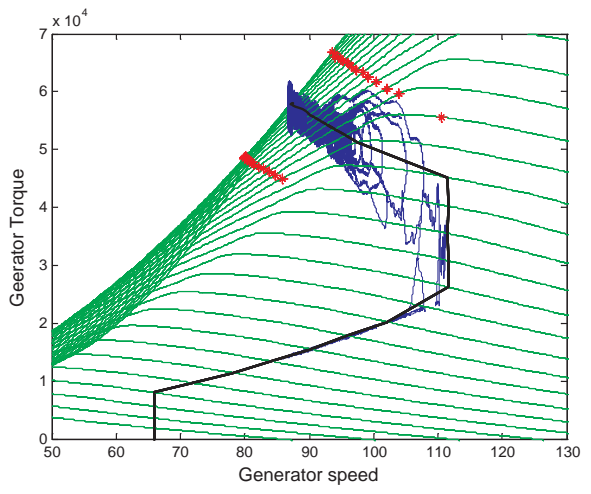

(b) application to simplified model.

Figure 8: Behaviour of the turbine on the torque/speed plane; red dots indicate $\pm 20 \%$ at wind speed above rated.

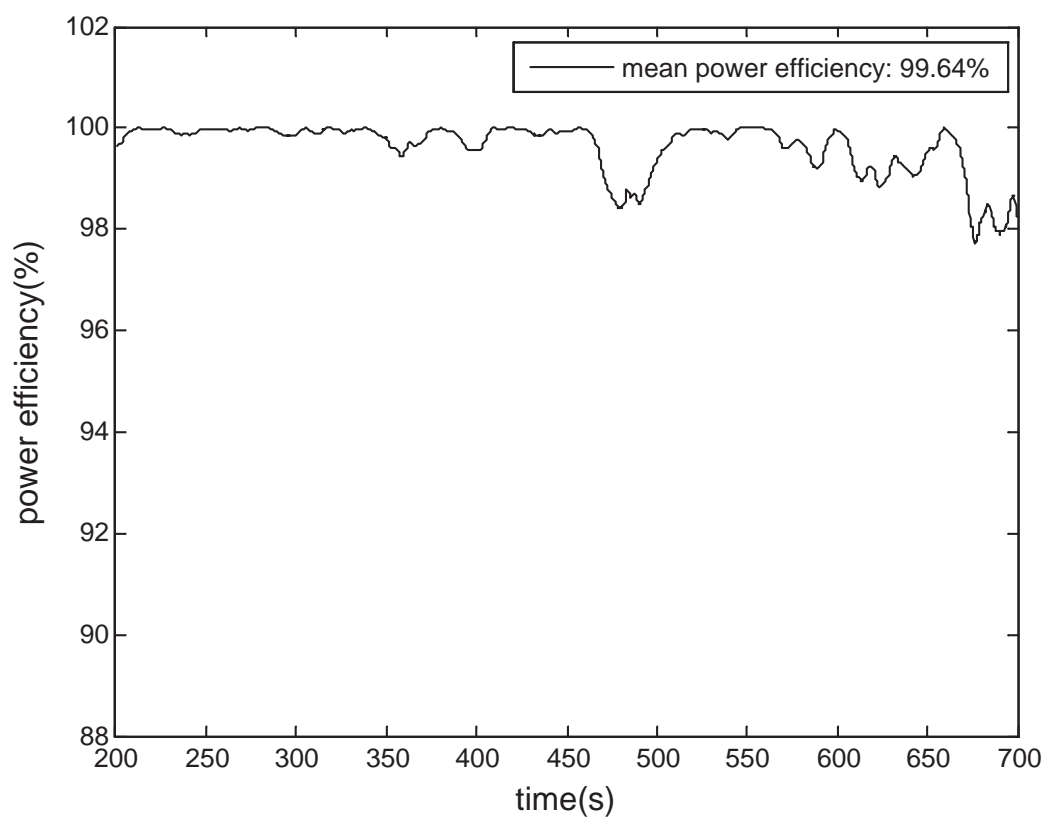

Figure 9: Power efficiency; 1 turbine in a cluster. 


\section{Collective Control}

Initially, the controller designed in Section 3 has been applied to the model for a cluster of 5 wind turbines. It responds to the average of $y_{i}(i=1, \ldots, N)$ from equation (6), (12) or (14), depending on the current operating mode. In this approach, the controller tends to perform satisfactorily when $N$ is relatively small. However, as it reaches 5, the performance becomes poorer because wind speed would be less uniform across a larger cluster than a smaller cluster, hence the difference between any $y_{i}$ and the average would increase.

For improved results, a new collective strategy is introduced in this section to take into account the worst control by choosing $y_{i}$ that is the furthest from the average when necessary. When wind speed is relatively uniform across the cluster, the average is chosen, otherwise, the controller chooses the turbine that is operating furthest from the average. The details of this strategy are described as follows, referring to Figure 10.

\subsection{Collective Control Strategy}

1. Error is defined as $y_{i}(i=1, \ldots, N)$ from equations (6), (12) and (14), depending on the current operating mode. Average error is the mean of $y_{i}(i=1, \ldots, N)$. Largest error refers to the absolute largest error.

2. If the largest error is in Region BR1/AR1, the largest error is the control input. It improves the performance significantly over the use of the average error as the control input. In order to enable smoother transition between the largest errors, a low-pass filter is incorporated. Thresholds 1 and 4 are defined in the same way as defining the $C_{p m a x}$ tracking curve in below rated wind speed; that is, using equation (6), but with a different $k$. Thresholds 2 and 3 are defined in the same way as defining the constant power curve in above rated wind speed, using equation (13), but with a different $P_{0}$.

3. If the largest error is in Region BR2/AR2, the average error is the control input. In this situation where wind speed is relatively uniform across the cluster, the use of the average error compared to the largest error improves the performance. If the largest error was used at all times, too much chattering would occur as the largest error "changes" - e.g. Turbine 1 has had the largest error so far, but now Turbine 2 has the largest error. When the average error is tracked, the low-pass filter used in Region BR1/AR1 is no longer required. 


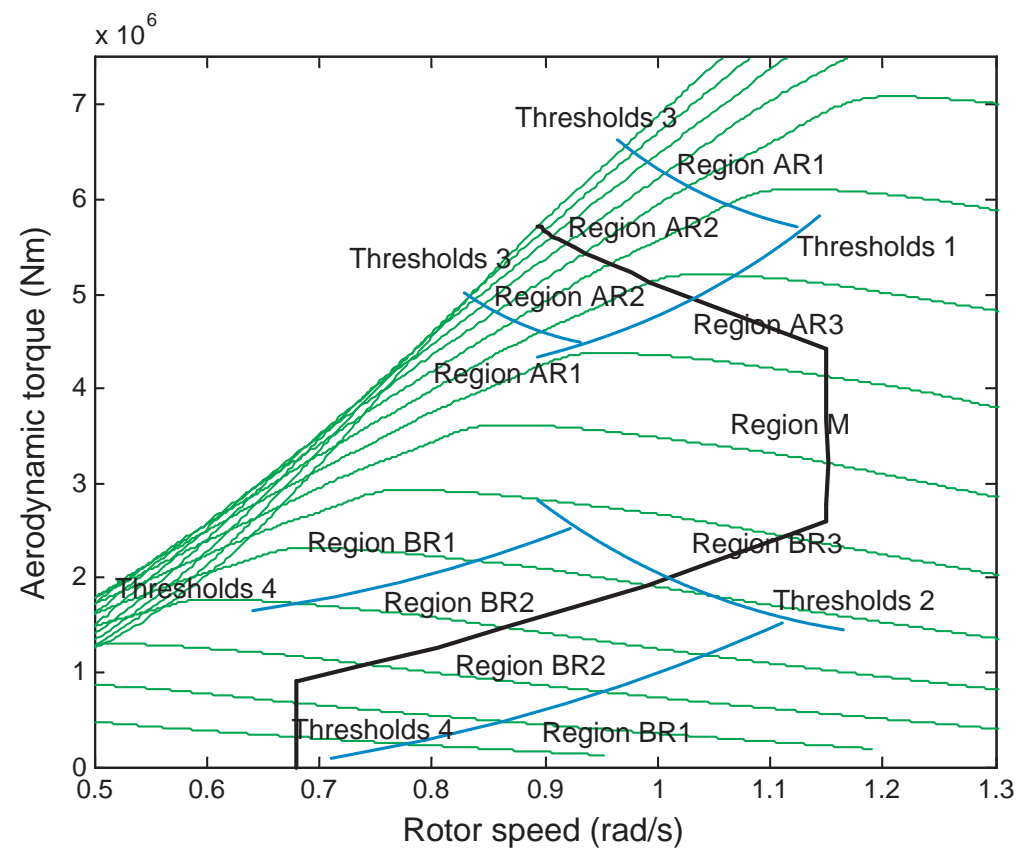

Figure 10: Collective control strategy.

4. If the average error is in Region BR3/AR3, the average error is used. This is to enable a smooth transition between Region BR3/AR3 and Region M; that is, if the largest error is used here, large transient overshoots in torque occurs as switching takes place, in addition to switching taking place incorrectly, i.e. at a wrong time.

5. To avoid chattering while crossing the thresholds, hysteresis needs to be included between

- Region BR1 and BR2

- Region AR1 and AR2

- Region BR1\&BR2 and Region BR3

- Region AR1\&AR2 and Region AR3

- Region BR3 and Region M

- Region AR3 and Region M 


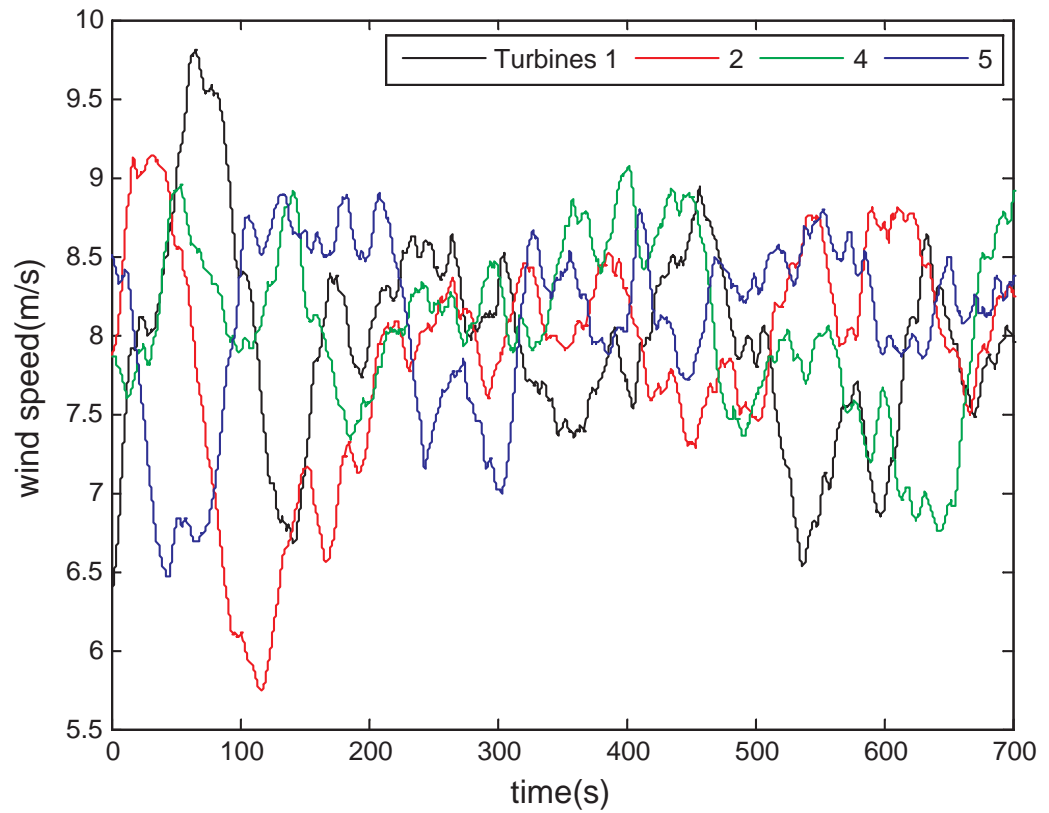

Figure 11: 4 effective wind speeds (mean of $8 \mathrm{~m} / \mathrm{s}$ ) used with the Matlab/SIMULINK models, turbines 1, 2, 4 and 5 .

\subsection{Simulation Results}

The Bladed model provides greater details for the structural loads, while the Matlab/SIMULINK model enables many turbines to be included in a cluster as previously mentioned. The cluster model thus consists of 4 Matlab/SIMULINK models (introduced in Section 2) and 1 Bladed model (of the same turbine). The two software packages are connected using StrathControl Gateway, a commercial software package that fully integrates the simulation. Modelling mismatch exists between the Bladed and Matlab/SIMULINK models, but it would also exist in real life. As introduced in Section 2, point wind speeds are obtained using Bladed and filtered to produce effective wind speeds to be incorporated into the Matlab/SIMULINK models. For the Bladed model, this procedure is not needed since the software allows users to design wind models more easily. 4 correlated wind speeds at a mean of $8 \mathrm{~m} / \mathrm{s}$, used with the Matlab/SIMULINK models, are depicted in Figure 11. Similar wind speeds are obtained for different mean wind speeds. 
Simulations in this section are carried out at mean wind speeds of $8,9.5$, $11,12,14$ and $16 \mathrm{~m} / \mathrm{s}$. Although switching takes place at mean wind speeds of 10 and $12 \mathrm{~m} / \mathrm{s}$ in the situation with each turbine having its own converter and controller, as shown in Section 3.6, in the situation where there are 5 turbines sharing a set of converter and controller, switching takes place at different mean wind speeds of 9.5 and $11 \mathrm{~m} / \mathrm{s}$. Therefore, 9.5 and $11 \mathrm{~m} / \mathrm{s}$, instead of 8 and $10 \mathrm{~m} / \mathrm{s}$, are chosen. This is because at any mean wind speed, the range of rotor speed is significantly reduced as the collective controller responds to the average of $y_{i}(i=1, \ldots, N)$ in comparison to the situation with each turbine having its own converter and controller.

Figures 12 and 13 depict the performance of the control strategy on the speed/torque planes. In comparison to the situation with each turbine having its own converter and controller, Figure 13 depicts greater drive-train load transients and larger fluctuations in generator power, especially in Turbines 4 and 5, which cross over $\pm 20 \%$. Referring to Figure 12, increased loads on the rotor can be surmised. Variance of the measurements of Turbine 3 is larger than the others since the Bladed model includes more dynamics than the Matlab/SIMULINK model, e.g. unsteady aerodynamics and rotational sampling.

The power efficiencies and their mean at wind speed below rated (i.e. $8 \mathrm{~m} / \mathrm{s}$ ) are plotted in Figure 14 for each turbine. Turbine 3 is excluded here since the direct calculation of its power efficiency cannot be attained in Bladed, as explained in Section 3.6. Despite the increased number of turbines, they stay relatively high, with the average and the lowest power efficiencies exceeding $98 \%$ and $95 \%$, respectively. When Rotor $\mathrm{A}$ is employed, the power efficiencies are significantly lower, with the average and the lowest power efficiencies not exceeding $80 \%$ and $60 \%$ [30]. This is the reason that Rotor B instead of Rotor A is utilised in this study even though Rotor A is more suitable for stall-regulated operations.

The results in this section depict that the performance of each turbine degrades compared with the situation with each turbine having its own converter and controller. However, the deficit as a result of this degradation could be outweighed by the savings that could be made by sharing a set of converter and controller among 5 turbines. Furthermore, the results would improve significantly if improved rotors can be utilised.

As each turbine experiences a different wind speed, the state of each turbine deviates from the required control strategy to the extent that drive-train torque and rotor speed transients are increased as previously mentioned. 
Table 1: Performance indices for 1, 3 and 5 turbine wind farm

\begin{tabular}{|c|c|c|}
\hline $\begin{array}{c}\text { Number of } \\
\text { turbines }\end{array}$ & $\begin{array}{c}\text { Average duration outside } \\
\text { the limits }(\%)\end{array}$ & $\begin{array}{c}\text { Largest deviation } \\
(\%)\end{array}$ \\
\hline 1 & 0 & 9.61 \\
\hline 3 & 1.67 & 26.7 \\
\hline 5 & 2.68 & 29.8 \\
\hline
\end{tabular}

Clearly, the deviation should become larger as the number of turbines increases, and turbines would eventually operate outside the $20 \%$ limits depicted (in red) in Figures 8 and 13. The average duration of the turbines' operation outside the limits is tabulated in Table 1 for wind farms of 1, 3 and 5 turbines. Since the limits are only crossed when switching from modes 3 to 4 , the average duration (in \%) outside the limits is calculated only at the mean wind speed at which the switching takes place. Moreover, the largest deviation from the control design curve in percentage is also recorded in the table. Note that the Matlab/Simulink model simulates the turbines for the table. The result demonstrates that, as the number of turbines in each cluster increases, the turbines deviate more both in time and magnitude from the required control strategy as expected. 

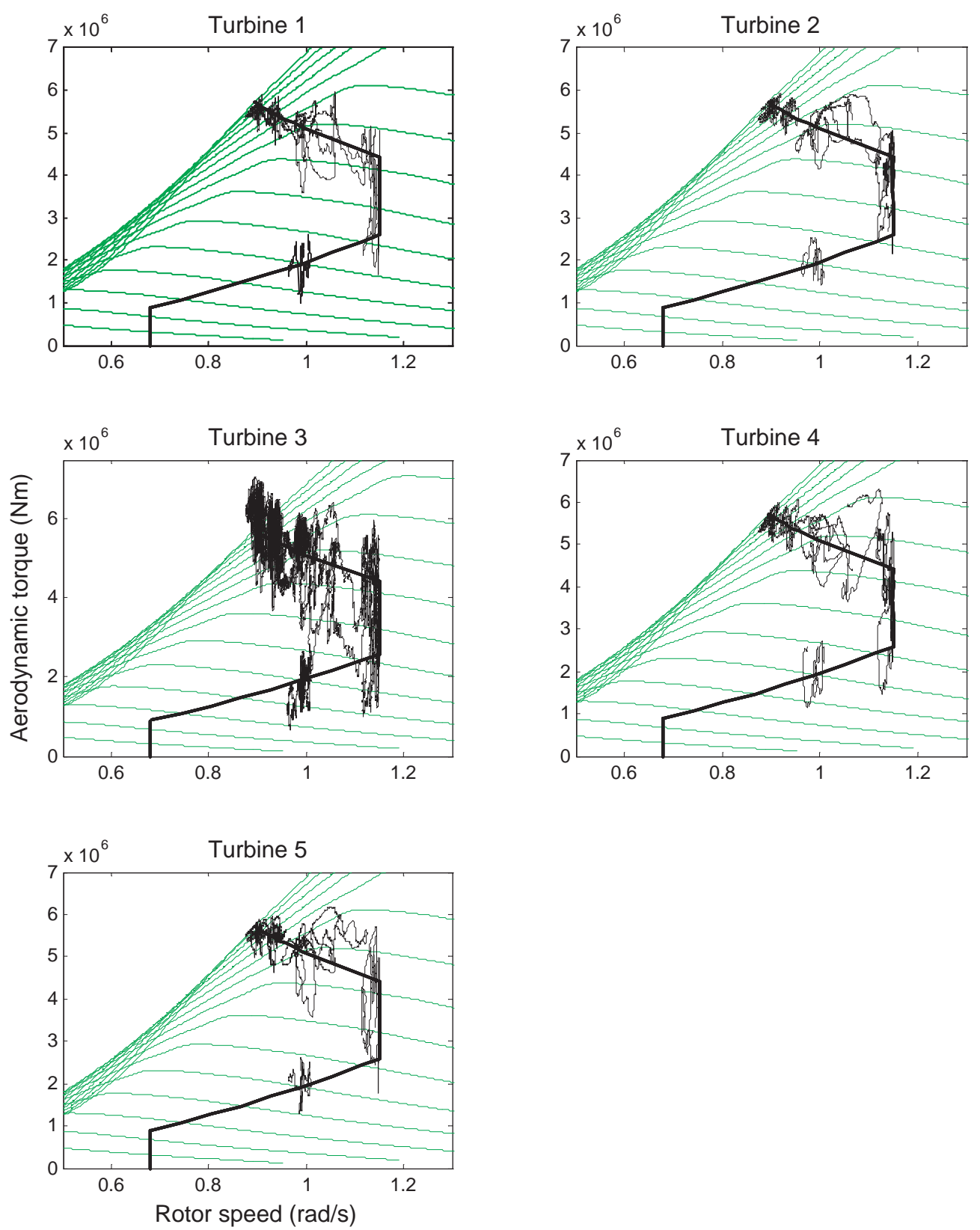

Figure 12: Turbines 1 to 5; Behaviour of each turbine on the torque/speed plane. 

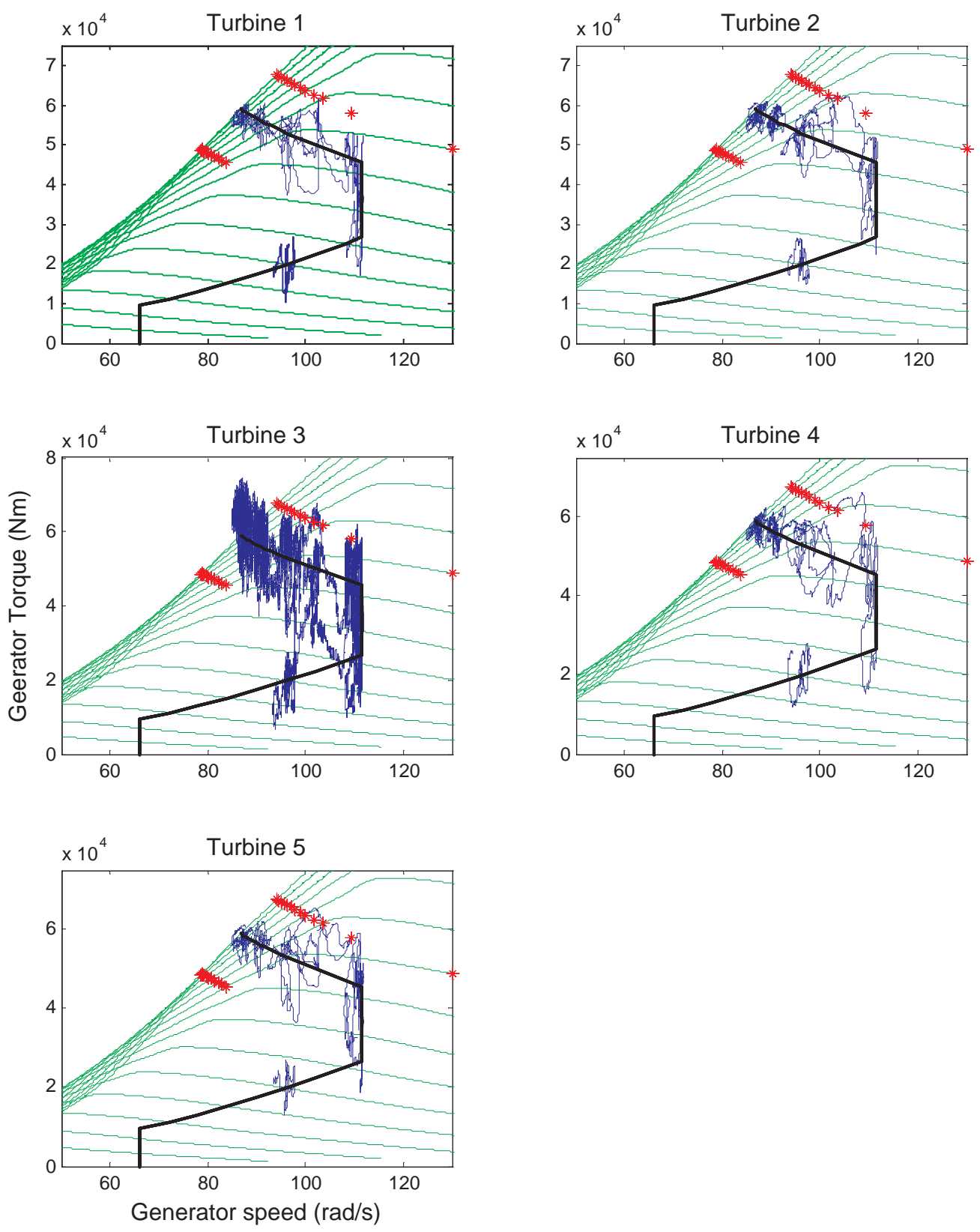

Figure 13: Turbines 1 to 5; Behaviour of each turbine on the torque/speed plane. 


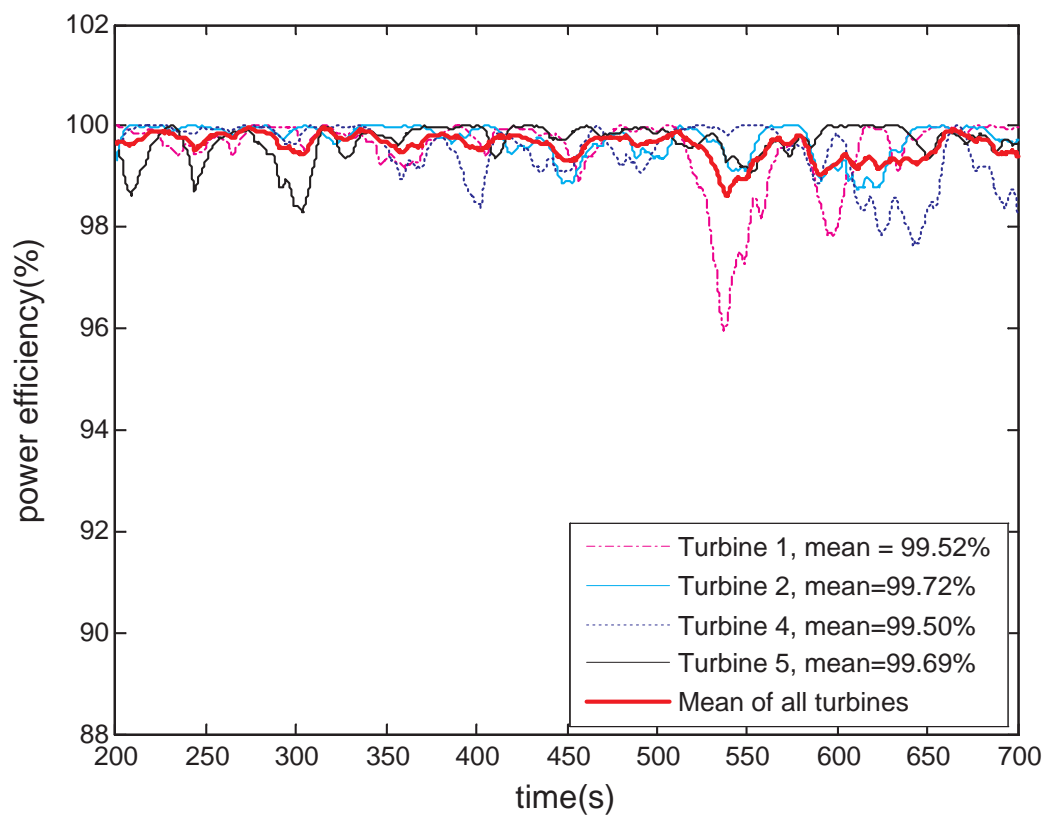

Figure 14: Power efficiency; 5 turbines in a cluster. 


\section{Conclusions and Future Work}

Equations from [9] are exploited for modelling a nonlinear wind turbine. The parameters of the Supergen 5MW exemplar turbine are exploited. In order to provide greater damping - hence to ameliorate the effect of drivetrain load transients and larger fluctuations in generated power as a result of having multiple turbines in a cluster - the model replaces the existing synchronous generator with an asynchronous induction generator.

An MPC based controller that operates over the full operational envelope of wind speed is designed based on the linearised models of this nonlinear model. It is first applied to a single turbine model (i.e. the Bladed model of the Supergen 5MW exemplar turbine), simulating a situation with each turbine having its own converter and controller. Subsequently, based on this full envelop controller, a collective controller for a cluster of 5 turbines, sharing a set of converter and controller, is designed. This collective control strategy acts in response to the poorest control when necessary as opposed to responding to the average control at all times. The strategy is assessed by application to a cluster model, consisting of 1 Bladed model and 4 Matlab/SIMULINK models. The Bladed model provides greater details for the structural loads, while the Matlab/SIMULINK model enables many turbines to be included in a cluster.

The simulation results demonstrate that the performance of each turbine degrades as expected in comparison to the situation with each turbine having its own converter and controller. However, the cost as a result of this degradation could be outweighed by the savings that could be earned by sharing a single set of converter and controller among 5 turbines. Moreover, the simulation results could improve significantly if optimal rotor design can be employed although such a rotor is not available for this study. Most importantly, the collective control strategy allows the power converter, which is one of the most vulnerable components of a wind turbine, to be separated from the turbines that are less accessible, e.g. due to bad weather, etc, and to be placed in a location where it is more accessible. Consequently, downtime as a result of potential generator problems would reduce, and the reliability of each turbine would improve due to simplification of the turbines. Reliability of each turbine is further improved by the use of constant-speed stall-regulated machines.

As future work, a rotor that is more suitable for the collective control strategy, i.e. a rotor that shares the characteristics of Rotor A and Ro- 
tor B, could be developed. Furthermore, at the cost of increased computational cost, more Bladed models could be employed to replace the Matlab/SIMULINK models since the Bladed model incorporates more dynamics enabling further results to be obtained, including all significant variables and loads and lifetime equivalent fatigue load estimates.

\section{Acknowledgements}

The authors wish to acknowledge the support of the EPSRC for the Supergen Wind Energy Technologies Consortium, grant number EP/H018662/1.

\section{References}

[1] T. Burton, D. Sharpe, N. Jenkins, E. Bossanyi, Wind Energy Handbook, John Wiley \& Sons, Ltd, 2001.

[2] F. D. Bianchi, H. D. Battista, R. J. Mantz, Wind Turbine Control Systems: Principles, Modelling and Gain Scheduling Design, Springer, 2006.

[3] S. M. Muyeen, R. Takahashi, J. Tamura, Operation and Control of HVDC-Connected Offshore Wind Farm, IEEE Transactions on Sustainable Energy 1 (1) (2010) $30-37$.

[4] E. Veilleux, P. W. Lehn, Interconnection of Direct-Drive Wind Turbines Using a Series-Connected DC Grid, IEEE Transactions on Sustainable Energy 5 (1) (2014) 139 - 147.

[5] B. Silva, C. Moreira, L. Seca, Y. Phulpin, J. Peas Lopes, Provision of Inertial and Primary Frequency Control Services Using Offshore Multiterminal HVDC Networks, IEEE Transactions on Sustainable Energy 3 (4) (2012) $800-808$.

[6] A. Egea-Alvarez, O. Gomis-Bellmunt, Sensorless control of a power converter for a cluster of small wind turbines, in: Proceedings of the EWEA, Barcelona, 2014.

[7] T. Wakui, R. Yokoyama, Reduction in Power Output Fluctuations by a Parallel-Variable Speed Operation using Multiple Wind Turbines, in: Proceedings of the EWEA, Vienna, 2013. 
[8] M. T. Iqbal, A. H. C. Coonick, L. L. Freris, Dynamic control of a standalone wind turbine, in: Proceedings of the 15th British Wind Energy Conference, York, UK, 1994, pp. 135 - 140.

[9] W. Leithead, B. Connor, Control of variable speed wind turbines: Dynamic models, International Journal of Control 73 (13) (2000) 1173 1188.

[10] C. Brosilow, B. Joseph, Techniques of Model-based Control, Prentice Hall Professional, 2002.

[11] M. Morari, C. Garcia, D. M. Prett, Model predictive control: Theory and practice-A survey, Automatica 25 (3) (1989) 335-348.

[12] I. Munteanu, A. I. Bratcu, N.-A. Cutululis, E. Ceangă, Optimal Control of Wind Energy Systems: Towards a Global Approach, Springer, 2007.

[13] X. Yang, F. Sotiropoulos, R. J. Conzemius, J. N. Wachtler, M. B. Strong, Large-eddy simulation of turbulent flow past wind turbines/farms: the Virtual Wind Simulator (VWiS), Wind Energy (2014) 1-21.

[14] F. Cuzzola, S. Aubrun, B. Leitl, Characterization of a wind turbine model for wake aerodynamics studies, Journal of Physics: Conference Series 555 (1) (2014) 1-7.

[15] Y. Nam, J. gi Kim, C. L. Bottasso, Maximal power extraction strategy in the transition region and its benefit on the AEP (annul energy product), Journal of Mechanical Science and Technology 25 (6) (2011) 1613-1619.

[16] B. M. Nagai, K. Ameku, J. N. Roy, Performance of a $3 \mathrm{~kW}$ wind turbine generator with variable pitch control system, Applied Energy 86 (2009) 1774-1782.

[17] H. Camblong, Digital robust control of a variable speed pitch regulated wind turbine for above rated wind speeds, Control Engineering Practice 16 (2008) 946-958.

[18] W. E. Leithead, Effective wind speed models for simple wind turbine simulations, in: Proceedings of $14^{\text {th }}$ British Wind Energy Association (BWEA) Conference, Nottingham, 1992. 
[19] P. Dorato, Linear-quadratic Control: An Introduction, Prentice Hall, 1995.

[20] M. J. Grimble, M. A. Johnson, Optimal control and stochastic estimation: theory and applications, Wiley, 1988.

[21] J. W. Helton, O. Merino, Classical Control Using $\mathrm{H}_{\infty}$ Methods: An Introduction to Design, SIAM, 1998.

[22] S. Skogestad, I. Postlethwaite, Multivariable Feedback Control: Analysis and Design, 2nd Edition, Wiley, 2005.

[23] W. Leithead, B. Connor, Control of variable speed wind turbines: Design task, International Journal of Control 73 (13) (2000) 1189 - 1212.

[24] J. A. Rossiter, Model-Based Predictive Control: a Practical Approach, CRC Press, 2005.

[25] J. M. Maciejowski, Predictive Control with Constraints, Prentice Hall, 2000 .

[26] D. J. Leith, W. E. Leithead, Appropriate realization of gain-scheduled controllers with application to wind turbine regulation, International Journal of Control 73 (11) (1996) 1001-1025.

[27] T. Bakka, H. R. Karimi, S. Christiansen, Linear parameter-varying modelling and control of an offshore wind turbine with constrained information, IET Control Theory Appl. 8 (1) (2014) 22-29.

[28] M. Cai, Z. Xiang, H. R. Karimi, Robust Sampled-Data $\mathrm{H}_{\infty}$ Control for Vibration Mitigation of Offshore Platforms with Missing Measurements, Mathematical Problems in Engineering 2014 (2014) 1-10.

[29] A. P. Chatzopoulos, Full Envelope Wind Turbine Controller Design for Power Regulation and Tower Load Reduction, Ph.D. thesis, University of Strathclyde (2011).

[30] S. Hur, W. Leithead, Feasibility study of offshore wind farms using simplified turbine, The supergen wind energy technologies consortium report, Industrial Control Centre and UK Wind Energy Research - Doctoral Training Centre, University of Strathclyde (2012). 